\title{
Constrained Contraceptive Choice: IUD Prevalence in Uzbekistan
}

\section{By Jennifer Barrett and Cynthia \\ Buckley}

Jennifer Barrett is a doctoral candidate, Department of Sociology, and graduate trainee, Population

Research Center, University of Texas, Austin, Texas, USA. Cynthia Buckley is associate professor, Department of Sociology, and William Blakesmore III Fellow, Institute for Innovation, Creativity and Capital, University of Texas, Austin, Texas, USA.
CONTEXT: Because individuals' and couples' needs vary, the availability of a variety of contraceptive choices is a key component of successful family planning programs. Most women in Uzbekistan rely on a single contraceptive method (the IUD), but it is unclear whether this reflects constraints on choice or simply a widespread preference.

METHODS: Nationally representative data from the 1996 Uzbekistan Demographic and Health Survey and the 2002 Uzbekistan Health Examination Survey were used to evaluate the relationship between demographic characteristics and knowledge and use of contraceptives among sexually active women. Separate multivariate regression analyses were performed for 1996 and 2002.

RESULTS: Nearly all sexually active women knew about contraceptives, and in 2002 most reported that they had ever used the IUD (71\%) or any modern method (77\%). In both surveys, women with higher levels of wealth (odds ratios, 2.2-3.1) and education (1.9-2.5) were more likely than other women to know about contraceptive methods other than the IUD. Higher levels of wealth and education, as well as urban residence and non-Uzbek ethnicity, were also associated with the use of contraceptives other than the IUD, although these relationships were generally weaker in 2002 than in 1996.

CONCLUSION: Despite the high prevalence of contraceptive use in Uzbekistan, the country's reproductive health program may be constraining method choice. Expanded programmatic efforts emphasizing choice from a range of methods are needed, especially among subgroups of women who have little knowledge or experience with methods other than the IUD.

International Family Planning Perspectives, 2007, 33(2):50-57
The focus of most family planning programs is to promote the adoption of modern methods of contraception. The ability to choose among multiple methods is central to the decision to practice contraception, ${ }^{1,2}$ because individuals' and couples' contraceptive needs differ according to their motivations for pregnancy prevention (delaying, spacing or stopping), their concerns about STIs and the cultural acceptability of available methods. When programs offer a range of contraceptive options, users have the ability to make active and educated method choices. ${ }^{3,4}$ Moreover, evidence indicates that contraceptive prevalence tends to increase if a wide variety of methods are available. 5,6 Within family planning programs, however, the decisions of institutional actors and the actions of health care providers can constrain contraceptive choices for women. In attempting to increase overall contraceptive prevalence, some national programs are charged with prescribing specific methods of contraception, rather than providing information aboutand access to-a variety of modern contraceptives.

Uzbekistan, the most populous of the former Soviet republics in Central Asia, had a one-method family planning regime when it was part of the Soviet Union: Abortion was the only widely available means of controlling fertility. ${ }^{7}$ Since Uzbekistan's independence in 1991, the country's extensive state-sanctioned family planning programs have been associated with reduced reliance on abortion and dramatic increases in contraceptive use. ${ }^{8}$ Yet, as during the Soviet period, one primary method of contraception remains dominant in Uzbekistan, in this case the IUD. Does knowledge of methods other than the IUD vary by women's social and demographic characteristics? Does the nearly universal adoption of the IUD in Uzbekistan reflect a preference shared across social groups, or is the choice of other contraceptive methods limited to certain groups of women? We examine these questions using data from the 1996 Uzbekistan Demographic and Health Survey (UDHS), the 2002 Uzbekistan Health Examination Survey (UHES) and interviews with medical professionals.

\section{Preferences and Contraceptive Choice}

The family planning literature identifies three interactive levels of factors that influence contraceptive method choice: institutional, clinical and individual. First, when governmental entities and international agencies seek to increase access to family planning and control fertility, their interest in expanding the range of methods offered may be secondary; as a result, method choice may be sacrificed due to issues of cost, supply and availability. In addition, cultural, structural and historic factors influence institutional preferences, which are slow to change. Second, the pref- 
erences of health care providers and family planning educators directly influence the information provided to clients, thus swaying women's decisions concerning method adoption. Specific method recommendations by doctors and other health care workers reflect their training and may be partially motivated by incentives to adopt the same preferences expressed by other individuals and institutions. ${ }^{9}$ Finally, couples' and individuals' perceptions about available contraceptive methods (based on their own and others' past experiences) and the information and ideas they gather through social interactions also play a substantial role in method choice. ${ }^{10,11}$

Although these three levels are interrelated, their relative degree of influence may differ substantially, particularly during fertility transitions. In a heavily centralized and powerful state such as Uzbekistan, institutional contraceptive preferences can be particularly influential, as they are amplified by government control of health care and family planning initiatives. Because institutional and provider-specific factors influence method familiarity, knowledge and availability, they can restrict individuals' contraceptive choices.

Potter attributes the tendency for women and health practitioners to gravitate toward one or two primary contraceptive methods to four socially based informational and attitudinal feedback loops. ${ }^{9}$ First, both groups may be motivated to select methods chosen by many other individuals-women because a popular method is likely to have stable availability, and providers because they can draw on the experience of colleagues. Second, learning on the part of producers, practitioners and users improves method efficacy, thus encouraging the choice of frequently used methods. Third, information concerning risks and benefits of commonly used methods is readily acquired through social networks. The final feedback loop involves social influence: Women and practitioners are induced by their peers to conform to local method norms. We argue that some groups of users, such as women with greater resources, enjoy expanded access to skilled professionals, method information and contraceptive sources, lessening the influence of such social pressures and feedback loops. As a result, these individuals may be more likely than other women to use less common contraceptive methods.

\section{The Uzbek Case}

During the Soviet period, when fertility was regulated primarily through induced abortion, women's knowledge about modern contraceptives was low in Uzbekistan. ${ }^{7}$ Barbieri and colleagues estimate that the number of abortions in Uzbekistan increased by 231\% between 1956 and $1973 .{ }^{12}$ In the 1970s, official warnings about the risks associated with hormonal contraceptives lessened interest in use of the pill and generated negative attitudes toward hormonal methods among medical professionals and the public. ${ }^{13}$ Other than abortion, methods of controlling fertility were seldom available in Uzbekistan until the mid-1980s, ${ }^{*}$ when the IUD was advocated in the local medical press. ${ }^{14}$

Today, awareness of modern contraceptive methods is quite high in Uzbekistan, as nearly 99\% of married women know of some form of modern contraception. In the 2002 UHES, the IUD was the most widely known method among married women (98\% were aware of it), yet high proportions had also heard about the pill (85\%), injectables (78\%) and male condoms (68\%). These figures represent increases over the already high proportions reported in the 1996 UDHS (although neither survey measured the depth of women's knowledge). ${ }^{15,16}$

Similarly, the prevalence of modern contraceptive use rose substantially after Uzbekistan's independence. In the 1996 UDHS, 65\% of married women reported ever-use of a modern contraceptive. ${ }^{15}$ Ever-use rates were even higher $(82 \%)$ six years later, according to data from the 2002 UHES. ${ }^{16}$ The UHES results also reveal that the abortion rate declined from 39 per 1,000 women to 28 per 1,000 women between the three-year periods 1991-1993 and 2000-2002. ${ }^{17}$ By 2005, unmet contraceptive need in Uzbekistan was estimated at $14 \%$ overall ( $7 \%$ for limiting and $7 \%$ for spacing). ${ }^{18}$

The rise in contraceptive knowledge and prevalence in Uzbekistan reflects the efforts of local, national and international groups. Several broad-based programs designed to expand contraceptive use and improve maternal and child health were initiated in the 1990s. In 1993, USAID launched a multisite Reproductive Health Service Expansion Program, which targeted rural areas and provided basic reproductive health training for health care workers, media-based education for the public and improved training in obstetrics. ${ }^{19}$ International organizations began shipping contraceptives as material assistance, focusing on the injectable, the pill and the IUD. According to some USAID officials in Tashkent, the emphasis on IUDs was in response to requests from the Uzbek government, which "simply want[ed] more and more IUDs delivered." 20

In the 1990s, many state reproductive health efforts were channeled through local mahallas (neighborhood organizations typically run by male elders and embedded within government social service funding), enhancing state control and the prioritization of government goals. Education programs typically targeted couples after the birth of their first child, focusing on contraceptive use for spacing and stopping births. ${ }^{21,22}$ Uzbekistan's strong central control of social services, high ethnic homogeneity (more than $80 \%$ of the population is ethnic Uzbek), tight reins on nongovernmental organizations and complete control of the media were conducive to the development of a national program on reproductive health. ${ }^{20}$

Centralized health care continues to provide an efficient channel for realizing state family planning goals. During the second author's fieldwork between 2001 and 2003, health professionals frequently reported that medical clinics, and in some cases even individual doctors, received un-

*Despite the generally low levels of contraceptive availability in Uzbekistan during the Soviet era, the few available analyses suggest that Uzbek women with higher socioeconomic status were able to control their fertility effectively (source: reference 12). 
written directives regarding IUD insertion quotas; many mentioned links between compliance and clinic funding. Numerous women remarked that the IUD was the only contraceptive option offered in government clinics. Although anecdotal, such persistent commentary points to a context of constrained choice, in which the notable advancements in contraceptive use may mask problems concerning the breadth of contraceptive knowledge and client access to a variety of methods. Reports from local and national nongovernmental organizations on the coercive environment in gynecology clinics also raise concerns regarding the heavy reliance on the IUD in Uzbekistan. ${ }^{23,24}$

Consistent with these reports, in the 2002 UHES, 73\% of married Uzbek women said that they had ever used the IUD, making it by far the most prevalent method of contraception; only 14\% of married women had ever used the male condom and 13\% had ever used the pill. ${ }^{16}$ Surveys of married women in Kazakhstan, the Kyrgyz Republic and Turkmenistan reveal similar patterns, although IUD dominance is greatest in Uzbekistan. ${ }^{25-27}$

As these data suggest, the strength of the state and the weakness of Uzbek civil society provide little possibility for effective oversight, monitoring or opposition. One young nurse in a Tashkent clinic remarked in 2002, "Workshops, [reproductive health] education [programs], these projects don't mean anything for most women....If a woman comes in, she will get an IUD inserted after the birth, regardless of what her mother-in-law thinks, her husband says or what she wants.... I do not know [pause] but am told this is for the best." The power hierarchy reflected in the nurse's comments appears at odds with the empowerment and choicebased approach favored by international family planning programs; instead, the emphasis is on practice, with little concern for attitudes or education. ${ }^{20}$

In summary, family planning programs have been successful in increasing the use of modern contraceptives and reducing the incidence of abortion in Uzbekistan, but their success in expanding clients' familiarity with and knowledge of a variety of methods, and in improving the ability to make informed choices, is less clear. ${ }^{21}$ Moreover, we know little about differentials in women's access to information and in the ability to choose from a variety of methods of contraception.

\section{DATA AND METHODS Data Sources}

We examine patterns of contraceptive knowledge and choice using data from the 1996 UDHS and the 2002 UHES. The two surveys used nationally representative samples of women

*Men were also surveyed in 2002 , but these data are not used in our analyses.

†These other modern contraceptives include male sterilization, implants, female condom, diaphragm, foam/jelly and emergency contraception; these methods were grouped in the 1996 survey but reported separately in 2002. Our measures of knowledge and use of modern contraceptive methods (which are identical to those used in the 1996 UDHS summary report) exclude lactational amenorrhea. Lactational amenorrhea was included as a form of modern contraception in the 2002 UHES summary report, but we chose to exclude it as a form of modern contraception because it was measured differently in the two surveys. aged 15-49, married and unmarried, which were obtained from a multistage, stratified cluster sample of households. Both data sets contain information on fertility, family planning, and contraceptive knowledge and use. The UDHS includes data on 4,415 women; the UHES, 5,463 women.* We restrict our analyses to sexually active women and exclude cases with missing data, which generates working samples of 4,004 women in 2002 and 3,113 women in 1996, nearly all of whom were currently or formerly married. In the analyses of contraceptive method knowledge, we further limit the sample to respondents who reported knowledge of any modern method (3,947 women in 2002 and 2,955 women in 1996). To account for sample design, we employ sample weights and correct for cluster effects.

\section{Dependent Variables}

We focus on two dependent variables in the study: knowledge of any modern method other than the IUD and everuse of any modern contraceptive. Among respondents who had heard of some modern method of contraception (female sterilization, the pill, the IUD, the injectable, the condom or other modern methods), ${ }^{\dagger}$ we compare women who had heard only of the IUD with those who had heard of other contraceptive methods. Next, we construct a multinomial dependent variable reflecting ever-use. Among sexually active women, we compare those who had never used modern contraceptives and those who had ever used a modern method other than the IUD with women who had used only the IUD. We compare women by ever-use instead of current use of modern contraceptives in order to examine the link between individual women's characteristics and their lifetime likelihood of choosing a method other than the IUD.

\section{Independent Variables}

We hypothesize that the women who are most likely to know about multiple contraceptive methods, and to have the ability to choose from a variety of methods, are those of relatively high socioeconomic status. If women in Uzbekistan are systematically coerced into using IUDs, those with lower levels of power (in terms of money, education and status) will be most susceptible to coercion. Thus, we examine whether individual women's social, demographic, economic and family structure characteristics are associated with their knowledge of multiple methods, their use of contraceptives and their choice of a method. We also examine whether the availability of contraceptive choices in Uzbekistan has changed over time.

A variety of individual characteristics, including age, parity, residence, ethnicity, wealth, education and employment, may influence women's access to contraceptive information and their choice of method. The lack of consistent formal reproductive health education in Uzbek schools and the very low levels of contraceptive knowledge reported by young women prior to sexual activity suggest that younger women may be less informed overall and more reliant on IUDs than older women. ${ }^{28}$ However, it is also possible that the rapid increases in contraceptive knowledge 


\begin{tabular}{|c|c|c|}
\hline Characteristic & $\begin{array}{l}1996 \\
(\mathrm{~N}=3,113)\end{array}$ & $\begin{array}{l}2002 \\
(\mathrm{~N}=4,004)\end{array}$ \\
\hline \multicolumn{3}{|l|}{ Age } \\
\hline $15-24$ & 23.1 & 20.1 \\
\hline $25-39$ & 55.1 & 53.6 \\
\hline $40-49$ & 21.8 & 26.3 \\
\hline \multicolumn{3}{|l|}{ Living children } \\
\hline $0-3$ & 67.3 & 72.3 \\
\hline$\geq 4$ & 32.7 & 27.7 \\
\hline \multicolumn{3}{|l|}{ Residence } \\
\hline Rural & 61.2 & 58.6 \\
\hline Urban & 38.8 & 41.4 \\
\hline \multicolumn{3}{|l|}{ Ethnicity } \\
\hline Uzbek & 82.4 & 85.0 \\
\hline Other & 17.6 & 15.0 \\
\hline \multicolumn{3}{|c|}{ Attended university/institute } \\
\hline No & 87.7 & 88.3 \\
\hline Yes & 12.3 & 11.7 \\
\hline \multicolumn{3}{|c|}{ Worked outside the home $†$} \\
\hline No & 42.8 & 50.5 \\
\hline Yes & 57.2 & 49.5 \\
\hline Total & 100.0 & 100.0 \\
\hline
\end{tabular}

and practices in Uzbekistan may be concentrated among women in the primary reproductive ages, such that older women are less informed about contraceptives and more dependent on IUDs than women who are somewhat younger. To test the importance of age, we compare women younger than 25 and women aged 40 or older to the reference group, women aged 25-39.

Parity may also be a factor in contraceptive knowledge and use. In Uzbekistan, where first births tend to occur during the first year of marriage, we expect to see higher levels of contraceptive use among women with more living children. We compare woman who have four or more living children with those who have three or fewer. Although rural residents are targeted by national family planning programs, they often have less access to clinics and less exposure to media campaigns than do their urban counterparts. Anticipating lower general contraceptive knowledge and higher rates of IUD usage among rural women, we compare urban and rural residents. Ethnicity is tied to language and cultural norms and may affect access and reaction to family planning programs. We compare minority ethnic groups with ethnic Uzbeks.

To assess the importance of socioeconomic status, we

*To faciliate comparisons between years, we use the same eight-item scale in both surveys. However, in ancillary analyses not presented here, we used an extended list of durable goods for which data were available only in the 2002 survey (dishwasher, freezer, washing machine, vacuum, tape recorder, video player, video camera, camera, satellite antenna, sewing machine, knitting machine and personal computer); the results were similar to those presented in the main analysis. examine whether household material well-being and education are related to women's breadth of contraceptive knowledge and ever-use of contraceptive methods. We measure material well-being based on household ownership of eight items (telephone, electricity, radio, television, refrigerator, bicycle, motorcycle and car);* to create a wealth index, we calculated the natural log of the total number of items owned plus one, as per the process advocated by Bollen and colleagues. ${ }^{29}$ In addition, we compare women who had ever attended a university or institute with those who had less education.

Finally, because of their social interactions and economic resources, women who work outside of the home may have greater contraceptive knowledge than do women who do not work outside of the home. Kamp has noted that external work is important for many Uzbek women and enables them to support children and to expand traditional social roles and networks. ${ }^{30}$ Hence, we compare women who worked outside the home in the past year with those who did not.

To check for multicollinearity, we examined the correlation matrix of all independent variables. Correlations were less than 0.4 in 1996 and less than 0.5 in 2002. Additionally, we found that the variance inflation factor was less than 1.5 for each of our independent variables; values greater than 10 generally indicate a multicollinearity problem.

\section{Analytic Plan}

Do social, demographic, economic and family structure variables affect the breadth of contraceptive knowledge and patterns of contraceptive use reported by Uzbek women? To answer these questions, we first examine the importance of individual characteristics in predicting the likelihood that women had knowledge of contraceptives other than the IUD. Next, we compare women who had never used contraceptives and women who had used contraceptives other than the IUD with those who had used only the IUD. In each step of the analyses, we examine changes in the effect size and significance of individual characteristics between 1996 and 2002.

\begin{tabular}{|c|c|c|}
\hline Measure & $\begin{array}{l}1996 \\
(\mathrm{~N}=3,113)\end{array}$ & $\begin{array}{l}2002 \\
(N=4,004)\end{array}$ \\
\hline \multicolumn{3}{|c|}{ Ever used modern contraceptives } \\
\hline Any & 62.6 & 77.4 \\
\hline IUD & 56.2 & 70.9 \\
\hline Other & 18.2 & 28.8 \\
\hline \multicolumn{3}{|c|}{ Currently using modern contraceptives† } \\
\hline Any & 53.0 & 60.3 \\
\hline IUD & 47.1 & 51.7 \\
\hline Other & 5.9 & 8.6 \\
\hline \multicolumn{3}{|c|}{ Knowledge of modern contraceptives } \\
\hline Any & 94.9 & 98.6 \\
\hline IUD & 94.4 & 98.0 \\
\hline Other & 84.2 & 92.7 \\
\hline
\end{tabular}




\begin{tabular}{|c|c|c|}
\hline Characteristic & $\begin{array}{l}1996 \\
(\mathrm{~N}=2,955)\end{array}$ & $\begin{array}{l}2002 \\
(\mathrm{~N}=3,947)\end{array}$ \\
\hline \multicolumn{3}{|l|}{ Age } \\
\hline $15-24$ & $0.63(0.13)^{*}$ & $0.57(0.10)^{* * *}$ \\
\hline 25-39 (ref) & 1.00 & 1.00 \\
\hline $40-49$ & $0.97(0.16)$ & $0.64(0.11)^{*}$ \\
\hline \multicolumn{3}{|l|}{ Living children } \\
\hline $0-3$ (ref) & 1.00 & 1.00 \\
\hline$\geq 4$ & $0.67(0.13)^{*}$ & $1.15(0.23)$ \\
\hline \multicolumn{3}{|l|}{ Residence } \\
\hline Rural (ref) & 1.00 & 1.00 \\
\hline Urban & $1.62(0.39)^{*}$ & $1.27(0.28)$ \\
\hline \multicolumn{3}{|l|}{ Ethnicity } \\
\hline Uzbek (ref) & 1.00 & 1.00 \\
\hline Other & $1.26(0.37)$ & $0.67(0.15)$ \\
\hline Material well-being score (logged) & $3.14(0.81)^{* * *}$ & $2.15(0.48)^{* * *}$ \\
\hline \multicolumn{3}{|l|}{ Attended university/institute } \\
\hline No (ref) & 1.00 & 1.00 \\
\hline Yes & $1.92(0.55)^{*}$ & $2.46(0.84)^{* *}$ \\
\hline \multicolumn{3}{|l|}{ Worked outside the home $†$} \\
\hline No (ref) & 1.00 & 1.00 \\
\hline Yes & $0.77(0.11)$ & $1.44(0.21)^{*}$ \\
\hline
\end{tabular}

\section{RESULTS}

\section{Sample Characteristics}

In both surveys, most women were aged 25-39 (55\% in 1996 and 54\% in 2002), had no more than three children (67\% and $72 \%$, respectively) and lived in rural regions (61\% and $59 \%$; Table 1, page 53). The vast majority ( $82 \%$ and $85 \%$ ) were ethnic Uzbeks; the remaining respondents were primarily ethnic Russians (3\% and 4\%), Tajiks (3\% in each survey), Kazakhs (3\% in each survey) or members of other Central Asian ethnic groups (such as Kyrgyz, Turkmen, or other groups; not shown). Only $12 \%$ of women in each survey had ever attended a university or institute, but a substantial proportion ( $57 \%$ and $50 \%$ ) had worked outside the home during the past year. Respondents reported having, on average, 4.1 items from the wealth index in 1996 and 3.8 items in 2002 (not shown).

The majority of sexually active women (63\% in 1996 and $77 \%$ in 2002) reported having ever used modern contraceptives (Table 2, page 53). In 1996, more than half (56\%) of sexually active women reported ever having used the IUD, whereas fewer than one in five (18\%) reported ever having used any other modern method. By 2002, however, con-

*In ancillary pooled analyses (available from the authors on request), we tested interactions between survey year and individual characteristics to determine the statistical significance of changes in effects over time. These supporting analyses suggest that the associations between knowledge of non-IUD methods and two variables have changed between 1996 and 2002: The association with having more than three children diminished in strength $(p<.05)$, whereas the association with working outside the home became stronger $(\mathrm{p}<.01)$. traceptive use had increased and broadened: Seventy-one percent of all sexually active women had ever used the IUD, and almost one in three (29\%) had used another modern method. In 1996 and 2002, 53\% and 60\% of survey respondents, respectively, were currently using contraceptives (excluding women who were pregnant and those who were unsure of their pregnancy status). The vast majority of women reported that they had heard about other modern contraceptive methods, yet the IUD remained the most recognized and commonly used form of modern contraception.

\section{Multivariate Analyses}

In Table 3, we present, in separate multivariate models for 1996 and 2002, the odds that women who knew of any modern method had heard of a method other than the IUD versus the odds that they knew of the IUD only. Women aged 24 or younger were significantly less likely than women aged 25-39 to be aware of methods other than the IUD in both 1996 and 2002 (odds ratios, 0.6). Women aged 40 or older did not differ from the reference group in 1996, but had reduced odds of knowing methods other than the IUD in 2002 (0.6). These results indicate that contraceptive familiarity was generally broadest among women in the middle age-group.

Compared with women who had three or fewer children, those with four or more children had significantly lower odds of knowing modern methods other than the IUD versus knowledge of the IUD only in 1996 (0.7), but this association was no longer apparent in 2002. Urban residents had increased odds of knowing methods other than the IUD in 1996 (1.6), but not in 2002. As expected, material well-being (3.1 in 1996 and 2.2 in 2002) and higher education (1.9 and 2.5, respectively) were positive predictors of knowledge of other methods. Working outside the home was also a positive predictor (1.4), but only in 2002.*

Moving from contraceptive knowledge to practice, we use multinomial logistic regression to examine whether individual characteristics are associated with the use of contraceptive methods (Table 4). Specifically, for individual characteristics, we calculate the odds of having never used any modern method of contraception versus having ever used only the IUD, and the odds of having ever used a method other than the IUD versus having ever used only the IUD. Again, we present separate multivariate models for 1996 and 2002.

Both the youngest age-group (odds ratios, 3.3 in 1996 and 3.7 in 2002) and the oldest respondents (2.0 and 2.1, respectively) exhibited elevated odds of having never used modern contraceptives, compared with having ever used the IUD only. Having four or more children was associated with reduced odds of nonuse ( 0.4 and 0.3 ), perhaps reflecting the popularity of the IUD for stopping childbearing. Urban residence was associated with never-use, although only in 2002 (1.4). Having had employment outside of the home in the past year was associated with reduced odds of reporting no past use of modern contra- 
ceptives in 1996 (0.7), but not in 2002.*

The models in Table 4 also explore relationships between individual characteristics and the odds of having ever used a modern contraceptive method other than the IUD compared with having ever used only the IUD. Urban residence and non-Uzbek ethnicity were strong positive predictors of having ever used modern methods other than the IUD (vs. ever-use of the IUD only) in both survey years, although the size of the urban association declined across time (from 2.3 to 1.4). In contrast to the results for never-use of a modern contraceptive, material well-being and education were associated with elevated odds of having ever used a method other than the IUD. In 1996, the odds that a woman had ever used a method other than the IUD more than doubled for each one-unit rise in her logged material well-being score (2.4), and higher education was also associated with increased odds of having used an alternative method (1.8). These associations were smaller, though still significant, in 2002. Working outside of the home was linked with lower odds of using contraceptive methods other than the IUD in 1996 (0.8), but not in 2002. ${ }^{\dagger}$

\section{DISCUSSION}

Our study had two primary goals. The first was to assess the importance of individual characteristics in determining women's knowledge of contraceptive methods other than the IUD in Uzbekistan. We found that knowledge of these alternative methods differed sharply by women's age, material well-being and level of education, both in 1996 and in 2002. This suggests that individual characteristics are relevant for predicting women's knowledge of less widely used contraceptive methods, even when overall awareness of contraceptives is high.

We also examined patterns of social and demographic differences in women's ever-use of alternative contraceptive methods. We found that individuals who had never used a modern method and those who had ever used a method other than the IUD differed from women who had used only the IUD, supporting our hypothesis that women with higher levels of socioeconomic status tend to use a wider range of contraceptives. Our findings were largely stable across survey years, indicating little change in the relationship between socioeconomic characteristics and the use of methods other than the IUD.

Scholars and policymakers increasingly note that method choice is a key element of successful family planning programs. As more varied groups of people begin to use contraceptives, the method requirements for a population may become increasingly diverse. Previous research indicates that access to multiple contraceptive methods is a successful strategy for increasing overall prevalence. In Uzbekistan, success in increasing contraceptive use does not appear to have coincided with a widening of the contraceptive mix. Rather, the Soviet reliance on a single method of limiting fertility (abortion) has been replaced by the almost exclusive use of a different method (the IUD). More than 80\% of married women used modern contraceptive methods in 2002, ${ }^{16}$ a dramatic

\begin{tabular}{|c|c|c|c|c|}
\hline \multirow[t]{2}{*}{ Characteristic } & \multicolumn{2}{|c|}{$\begin{array}{l}\text { Never-use of modern } \\
\text { method vs. IUD ever-uset }\end{array}$} & \multicolumn{2}{|c|}{$\begin{array}{l}\text { Non-IUD ever-use vs. } \\
\text { IUD ever-use } \neq\end{array}$} \\
\hline & $\begin{array}{l}1996 \\
(\mathrm{~N}=3,113)\end{array}$ & $\begin{array}{l}2002 \\
(N=4,004)\end{array}$ & $\begin{array}{l}1996 \\
(\mathrm{~N}=3,113)\end{array}$ & $\begin{array}{l}2002 \\
(N=4,004)\end{array}$ \\
\hline \multicolumn{5}{|l|}{ Age } \\
\hline $15-24$ & $3.32(0.48)^{* * *}$ & $3.73(0.43)^{* * *}$ & $0.73(0.15)$ & $0.77(0.12)$ \\
\hline 25-39(ref) & 1.00 & 1.00 & 1.00 & 1.00 \\
\hline $40-49$ & $1.95(0.25)^{* * *}$ & $2.14(0.27)^{* * *}$ & $1.15(0.15)$ & $1.16(0.13)$ \\
\hline \multicolumn{5}{|l|}{ Living children } \\
\hline $0-3$ (ref) & 1.00 & 1.00 & 1.00 & 1.00 \\
\hline$\geq 4$ & $0.40(0.05)^{* * *}$ & $0.30(0.05)^{* * *}$ & $0.77(0.11)$ & $1.10(0.12)$ \\
\hline \multicolumn{5}{|l|}{ Residence } \\
\hline Rural (ref) & 1.00 & 1.00 & 1.00 & 1.00 \\
\hline Urban & $1.08(0.14)$ & $1.44(0.20)^{* *}$ & $2.31(0.44)^{* * *}$ & $1.37(0.16)^{* *}$ \\
\hline \multicolumn{5}{|l|}{ Ethnicity } \\
\hline Uzbek (ref) & 1.00 & 1.00 & 1.00 & 1.00 \\
\hline Other & $0.80(0.12)$ & $1.27(0.19)$ & $1.74(0.28)^{* * *}$ & $1.78(0.25)^{* * *}$ \\
\hline Material well-being score (logged) & $0.70(0.13)$ & $1.01(0.16)$ & $2.44(0.64)^{* * *}$ & $1.82(0.26)^{* * *}$ \\
\hline \multicolumn{5}{|l|}{ Attended university/institute } \\
\hline No (ref) & 1.00 & 1.00 & 1.00 & 1.00 \\
\hline Yes & $1.23(0.21)$ & $0.74(0.15)$ & $1.76(0.28)^{* * *}$ & $1.47(0.20)^{* *}$ \\
\hline \multicolumn{5}{|l|}{ Employment outside the home§ } \\
\hline No (ref) & 1.00 & 1.00 & 1.00 & 1.00 \\
\hline Yes & $0.66(0.07)^{* * *}$ & $1.01(0.11)$ & $0.76(0.10)^{*}$ & $1.11(0.10)$ \\
\hline
\end{tabular}

${ }^{*} \mathrm{p}<.05 .{ }^{* *} \mathrm{p}<.01 .{ }^{* * *} \mathrm{p}<.001$. + Comparison is between women who had never used a modern method and women who had used only the IUD. ¥Comparison is between women who had used a method other than the IUD and women who had used only the IUD. §In past year. Notes: ref=reference category. The findings in this table represent two multinomial logistic regressions. The first regression comprised the comparisons for 1996 (never-use of modern method vs. IUD ever-use, and non-IUD ever-use vs. IUD ever-use); the second regression comprised the corresponding comparisons for 2002. However, we have reordered the columns in this table to match the structure of the discussion in the article text.

improvement from the Soviet period, yet more than $85 \%$ of all users relied on the IUD. Anecdotal evidence indicates a strong state-level preference for the IUD in Uzbekistan, a preference reflected in the composition of international aid to promote family planning and the behavior of medical care professionals. These findings and observations raise questions regarding the structural context within which individuals' contraceptive decision making takes place.

Our analyses suggest that contraceptive choice in Uzbekistan is constrained, such that the only contraceptive option for many women is the IUD. Women who possess higher levels of material wealth or who are well educated appear to be more knowledgeable than other women about multiple contraceptive methods, and thus may be better able to choose from a variety of methods. Women who are highly educated, urban residents, relatively wealthy or not eth-

*Ancillary pooled analyses for 1996 and 2002 indicate a significant decline between surveys in the association between work outside the home and nonuse of contraception versus IUD use only $(\mathrm{p}<.01)$.

†Ancillary analyses using pooled data revealed significant changes between 1996 and 2002 in the use of methods other than the IUD. The decline in the size and statistical significance of the association between urban residence and the use of other methods $(p<.01)$ may indicate diminishing residential effects. Working outside the home was negatively related to the use of other methods in 1996, but the relationship was not significant in 2002 (change between years significant at $p<.05$ ). 
nic Uzbeks have elevated odds of ever having used a method other than the IUD. These findings are consistent with the argument that contraceptive choices are determined within a multilevel network of influences related to method availability, to women's and providers' knowledge of and experience with various methods, and to social pressures. Individual characteristics affect women's responses to these influences and pressures, widening or constricting channels of access to contraceptive information, supplies and services. Compared with individuals with higher socioeconomic status, women with relatively few resources may be more strongly influenced by structural or programmatic constraints on women's knowledge of and access to contraceptives, and by strong encouragement for IUD adoption from the medical community in Uzbekistan.

The relationship between most individual characteristics and the use of alternative contraceptive methods weakened between 1996 and 2002, which may indicate increased equity in method access, perhaps due to family planning efforts that focus on rural, poor, less educated and unemployed women. Nonetheless, substantial differentials remain. Expanded programmatic efforts emphasizing choice from a range of methods are needed, especially among groups of women who almost exclusively use the IUD.

This investigation raises several questions for future analysis. Examinations of the content of family planning materials and family planning directives to state clinics can provide better understanding of the institutional context in Uzbekistan and enable evaluations of the means and motives behind the observed state preferences for the IUD. Additional investigation into women's preferences and priorities in method selection would further illuminate the demand for methods other than the IUD and shed light on how women's contraceptive needs vary according to their desire to delay, space or prevent future births. More research on the level of method knowledge and availability in Uzbekistan is also justified by our findings. Observation of workers in public health clinics and birthing hospitals may clarify the role that medical professionals play in influencing method choice. Sadly, given the increasingly restrictive research climate in Uzbekistan, ${ }^{31,32}$ the possibilities for more detailed qualitative work are presently limited.

Our findings indicate a potential conflict between international goals concerning successful reproductive health programs and the ways in which state and institutional interests in Uzbekistan influence individual decision making. They also suggest that a critical evaluation of Uzbekistan's reproductive health achievements and remaining needs is warranted, as such an assessment can contribute to our understanding of institutional processes and individual decision making in the realm of reproductive health.

\section{REFERENCES}

1. Bruce J, Fundamental elements of the quality of care: a simple framework, Studies in Family Planning, 1990, 21(2):61-91.

2. United Nations, Program of action of the 1994 International Conference on Population and Development (Chapters I-VIII), Population and Development Review, 1995, 21(1):187-213.
3. Cates W, Jr., and Stone KM, Family planning, sexually transmitted diseases and contraceptive choice: a literature update, part II, Family Planning Perspectives, 1992, 24(3):122-128

4. Walsh J, Contraceptive choices: supporting effective use of methods, in: Ravindran TKS, Berer M and Cottingham J, eds., Beyond Acceptability: Users' Perspectives on Contraception, London: World Health Organization and Reproductive Health Matters, 1997, pp. 89-96

5. Phillips JF et al., Determinants of reproductive change in a traditional society: evidence from Matlab, Bangladesh, Studies in Family Planning, 1988, 19(6):313-334

6. Ross J et al., Contraceptive method choice in developing countries, International Family Planning Perspectives, 2002, 28(1):32-40.

7. David HP, ed., From Abortion to Contraception: A Resource to Public Policies and Reproductive Behavior in Central and Eastern Europe from 1917 to the Present, Westport, CT, USA: Greenwood Press, 1999.

8. Karimov SI, Introduction, in: Uzbekistan Institute of Obstetrics and Gynecology and Macro International, Uzbekistan Demographic and Health Survey, 1996, Calverton, MD, USA: Uzbekistan Institute of Obstetrics and Gynecology and Macro International, 1997, pp. 1-11.

9. Potter JE, The persistence of outmoded contraceptive regimes: the case of Mexico and Brazil, Population and Development Review, 1999, 25(4):703-739

10. Entwisle B et al., Community and contraceptive choice in rural Thailand: a case study of Nang Rong, Demography, 1996, 33(1):1-11.

11. Rutenberg N and Watkins SC, The buzz outside the clinics: conversations and contraception in Nyanza Province, Kenya, Studies in Family Planning, 1997, 28(4):290-307.

12. Barbieri M et al., Nuptiality, fertility, use of contraception, and family policies in Uzbekistan, Population Studies, 1996, 50(1):69-88.

13. Arutunyan A, Abortion in Russia: no big deal, Moscow News, Nov. 25, 2004, <http://www.mosnews.com/feature/2004/11/25/ abortion.shtml>, accessed May 1, 2007.

14. Narzykulova SA, Khasanova RG and Sadykova LG, Results of the use of different methods of contraception, Medical Journal of Uzbekistan, 1985, Vol. 2, pp. 44-46 (in Russian)

15. Asadov DA et al., Contraception, in: Uzbekistan Institute of Obstetrics and Gynecology and Macro International, Uzbekistan Demographic and Health Survey, 1996, Calverton, MD, USA: Uzbekistan Institute of Obstetrics and Gynecology and Macro International, 1997, pp. 47-68.

16. Sullivan JM and Kamilov AI, Contraception, in: Analytical and Information Center, Uzbekistan Ministry of Health; State Department of Statistics, Uzbekistan Ministry of Macroeconomics and Statistics; and ORC Macro, Uzbekistan Health Examination Survey 2002, Calverton, MD, USA: Analytical and Information Center, State Department of Statistics and ORC Macro, 2004, pp. 53-62.

17. Sullivan JM and Kamilov AI, Induced abortion, in: Analytical and Information Center, Uzbekistan Ministry of Health; State Department of Statistics, Uzbekistan Ministry of Macroeconomics and Statistics; and ORC Macro, Uzbekistan Health Examination Survey 2002, Calverton, MD, USA: Analytical and Information Center, State Department of Statistics and ORC Macro, 2004, pp. 63-69.

18. United Nations Population Fund (UNFPA), Uzbekistan, <http://www.unfpa.org/profile/uzbekistan.cfm>, accessed Feb. 26, 2006.

19. Rich V, Uzbekistan: family contraceptive counselling, Lancet, 1993, 341(8858):1466-1467.

20. Buckley $C$, Challenges to integrating sexual health issues into reproductive health programs in Uzbekistan, Studies in Family Planning, 2006, 37(3):155-168

21. Buckley C, Barrett J and Asminkin YP, Reproductive and sexual health among young adults in Uzbekistan, Studies in Family Planning, 2004, 35(1):1-14.

22. Sievers EW, Uzbekistan's mahalla: from Soviet to absolutist residential community associations, Chicago-Kent Journal of International and Comparative Law, 2002, Vol. 2, pp. 91-158.

23. Boboev M, Bukharbaeva $G$ and Rasulov Y, Birth control by decree in Uzbekistan, Institute for War and Peace Reporting, Apr. 29, 2005, $<$ http:/ iwpr.net $/$ p $=$ rca\&s $=$ f\&o $=238837 \& a p c \_s t a t e=h e n i r c a 2005>$, accessed Feb. 7, 2007.

24. UNFPA and Population Reference Bureau, Country Profiles for 
Population and Reproductive Health: Policy Developments and Indicators 2003, New York: UNFPA, and Washington, DC: Population Reference Bureau, 2003.

25. Builashev TS, Doskeeva JA and Mysyraliev MS, Contraception, in: Research Institute of Obstetrics and Pediatrics, Ministry of Health of the Kyrgyz Republic and Macro International, Kyrgyz Republic Demographic and Health Survey, 1997, Calverton, MD, USA: Research Institute of Obstetrics and Pediatrics, Ministry of Health of the Kyrgyz Republic and Macro International, 1998, pp. 41-62.

26. Seyhan H and Salkhanova A, Contraception, in: Kazakhstan Academy of Preventive Medicine and Macro International, Kazakhstan Demographic and Health Survey 1999, Calverton, MD, USA: Kazakhstan Academy of Preventive Medicine and Macro International, 1999, pp. 55-78.

27. Turayeva SM, Bekmuradov NM and Weinstein K, Contraception, in: Gurbansoltan Eje Clinical Research Center for Maternal and Child Health (GECRCMCH), Turkmenistan Ministry of Health and Medical Industry and ORC Macro, Turkmenistan Demographic and Health Survey 2000, Calverton, MD, USA: GECRCMCH and ORC Macro, 2001, pp. 49-68.

28. Tokhtakhodjaeva M, Traditional stereotypes and women's problems in post-Soviet Uzbekistan: a survey of the mass media, Women Living under Muslim Laws, 2000, <http://www.wluml.org/english/ pubsfulltxt.shtml?cmd[87]=i-87-2745>, accessed Mar. 1, 2006.

29. Bollen KA, Glanville JL and Stecklov G, Economic status proxies in studies of fertility in developing countries: does the measure matter? Population Studies, 2002, 56(1):81-96.

30. Kamp M, Gender ideals and income realities: discourses about labor and gender in Uzbekistan, Nationalities Papers, 2005, 33(3):403-422.

31. MacWilliam I, Outlook bleak in wake of Andijan, BBC News, May 11, 2006, <http://news.bbc.co.uk/1/hi/world/asia-pacific/4761821.stm>, accessed May 6, 2007.

32. U.S. Department of State, Travel warning: Uzbekistan, Apr. 25, 2007, $<$ http://travel.state.gov/travel/cis_pa_tw/tw/tw_2533.html>, accessed May 6, 2007

\section{RESUMEN}

Contexto: Tomando en cuenta que varían las necesidades de las personas y de las parejas, la disponibilidad de una diversidad de opciones de anticonceptivos es un componente clave para lograr que sean exitosos los programas de planificación familiar. La mayoría de las mujeres de Uzbekistán utilizan únicamente un método anticonceptivo (el DIU), aunque no se sabe con precisión si esto refleja limitaciones de elección o simplemente que hay una gran preferencia por este método.

Métodos: Se utilizaron datos representativos obtenidos a nivel nacional, recopilados por la Encuesta Demográfica y de Salud de Uzbekistán, realizada en 1996 y por la Encuesta de Examen de la Salud de Uzbekistán de 2002, para evaluar la relación que existe entre las características demográficas y el conocimiento y uso de anticonceptivos entre las mujeres sexualmente activas. Se realizaron análisis independientes de regresión logística de multivariables, con los datos obtenidos en 1996 y 2002. Resultados: Casi todas las mujeres sexualmente activas tenian conocimientos acerca de métodos anticonceptivos y en la encuesta de 2002 la mayoría indicó que alguna vez habían utilizado un DIU (71\%) o algún otro método (77\%). En ambas encuestas, las mujeres con mayor nivel económico (coeficientes de probabilidades de 2,2-3,1) y de educación (1,9-2,5) fueron más proclives que otras mujeres a tener un mayor conocimiento acerca de métodos anticonceptivos que no fuera únicamen- te el DIU. Los niveles económico y de educación más elevados, así como el lugar de residencia urbana, o su origen étnico, no uzbekistano, también fueron características que estuvieron relacionadas con el uso de otros anticonceptivos que no fueran el DIU; no obstante, estas relaciones fueron más débiles en la encuesta realizada en 2002 que en la de 1996.

Conclusión: A pesar de la elevada prevalencia del uso de anticonceptivos en Uzbekistán, el programa de salud reproductiva de este país probablemente está limitando las opciones del uso de otros métodos. Es necesario que el programa amplie y ofrezca una amplia gama de métodos, especialmente entre los subgrupos de mujeres que tienen pocos conocimientos o experiencia con otros métodos que no sea el DIU.

\section{RÉSUMÉ}

Contexte: Face à la diversité des besoins des personnes et des couples, la variété des choix contraceptifs proposés est essentielle au succès des programmes de planification familiale. La plupart des femmes d'Ouzbékistan pratiquent une même méthode contraceptive (le stérilet), mais il n'est pas établi que ce choix reflète une sélection limitée ou, simplement, une préférence généralisée.

Méthodes: Les données nationalement représentatives des enquêtes EDS 1996 et Health Examination Survey 2002 d'Ouzbékistan servent à évaluer le rapport entre les caractéristiques démographiques et la connaissance et pratique de la contraception parmi les femmes sexuellement actives. Des analyses de régression multivariées distinctes ont été effectuées pour 1996 et 2002. Résultats: Presque toutes les femmes sexuellement actives étaient au courant de la contraception. En 2002, la plupart ont déclaré avoir utilisé le stérilet (71\%) ou une méthode moderne quelconque (77\%). Dans les deux enquêtes, les femmes aux niveaux supérieurs de richesse (rapport de probabilités, 2,2-3,1) et d'instruction $(1,9-2,5)$ se sont avérées plus susceptibles de connaître de méthodes contraceptives autres que le stérilet. Les niveaux supérieurs de richesse et d'instruction, de même que la résidence en milieu urbain et l'ethnicité non-ouzbèque, étaient aussi associés à l'usage de contraceptifs autres que le stérilet, bien que ces rapports soient généralement plus faibles en 2002 qu'en 1996.

Conclusion: Malgré la haute prévalence de la pratique contraceptive en Ouzbékistan, il se peut que le programme de santé génésique du pays entrave les choix de méthode. De vastes efforts programmatiques mettant l'accent sur le choix parmi différentes méthodes doivent être déployés, surtout parmi les sousgroupes de femmes dont la connaissance ou l'expérience des méthodes autres que le stérilet est faible.

\section{Acknowledgments}

This research was supported by a fellowship from the Don and Sybil Harrington Foundation for the first author and a Short-Term Travel Grant from the International Research and Exchanges Board for the second author. We would like to express our thanks to Thomas Pullum for providing helpful comments on an earlier version of models presented here.

Authorcontact:jbarrett@prc.utexas.edu 